\title{
Changes in physical activity and short-term changes in health care charges: a prospective cohort study of older adults
}

\author{
Brian C. Martinson, Ph.D., ${ }^{\text {a } *}$ A. Lauren Crain, Ph.D., ${ }^{\text {a Nicolaas P. Pronk, Ph.D., }}$ \\ Patrick J. O'Connor, M.D., MPH, ${ }^{\mathrm{a}}$ and Michael V. Maciosek, Ph.D. ${ }^{\mathrm{a}}$ \\ ${ }^{a}$ HealthPartners Research Foundation, 3105 East 80th Street, Mod C, Suite 299, Bloomington, MN 55425, USA \\ ${ }^{\mathrm{b}}$ HealthPartners Center for Health Promotion, 3105 East 80th Street, Bloomington, MN 55425, USA
}

\begin{abstract}
Background. Better understanding the impact of changes in physical activity behavior on short-term health care charges may inform resource allocation decisions to increase population levels of physical activity. This study examines the prospective relationship of changes in physical activity status on short-term changes in health care charges for older adults.

Methods. A prospective cohort study was done on a stratified random sample of 2,393 adults aged 50 and older enrolled in a Minnesota health plan, predicting changes in resource use between two periods (September 1994 to August 1995 and September 1996 to August 1997) based on billed health care charges.

Results. After adjustment for age, gender, comorbidity, smoking status, and body mass index, all physical activity states had declining health care charges, relative to those who were consistently inactive. Subjects who increased their physical activity from $0-1$ to $3+$ days/week had significant declines in their mean annualized total charges $(-\$ 2,202, P<0.01)$ relative to those who remained inactive.

Conclusions. Increased physical activity among older adults is associated with lower health care charges within 2 years, relative to charges for those who were persistently inactive. These cost savings may justify investments in effective interventions to increase physical activity in older adults.
\end{abstract}

(C) 2003 American Health Foundation and Elsevier Inc. All rights reserved.

Keywords: Physical activity; Health surveys; Costs and cost analysis

\section{Introduction}

Low levels of physical activity are consistently associated with adverse health outcomes, and a sedentary lifestyle characterized by inadequate levels of physical activity is endemic among U.S. adults, particularly among older adults [1]. Moreover, older adults experience a disproportionate burden of illness associated with sedentary behavior and low cardiorespiratory fitness [1-3]. Low levels of physical activity have been associated with high short-term health care charges in prospective [4] and retrospective analyses [5]. However, there are few data that relate change in physical activity level to change in health care costs. If

\footnotetext{
* Corresponding author. Fax: +1-952-967-5022.

E-mail address: Brian.C.Martinson@HealthPartners.com (B.C. Martinson).
}

increasing levels of physical activity can be shown to lower health care charges, or if decreasing activity levels predict higher charges, then strategic investments in programs to support active lifestyles may be justified from the economic as well as the clinical point of view.

Most previous studies of physical activity and health care costs have relied on a single baseline assessment of physical activity, with measurement of subsequent health care charges [4,5]. To further test the hypothesis that low levels of physical activity and higher health care costs are causally related, analyses need to extend beyond single-exposure assessments and measure change in physical activity over time, preferably using multiple measures from individuals. Such analyses would permit estimation of the health care costs that may be averted by interventions that increase physical activity.

In this study, we examined the impact of changes in 
physical activity over the course of a single year with short-term changes in health care charges incurred in a randomly selected cohort of health plan members ages 50 years or older.

\section{Methods}

The study was conducted at HealthPartners, a Minnesota health plan with 700,000 members in either owned or contracted clinics. We surveyed a stratified random sample of 8,000 health plan members by mail in August 1995, and sent postcard reminders 1 week after the initial survey mailing. A replacement survey was mailed to nonrespondents 3 weeks after initial mailing, with telephone follow-up of those not responding to the replacement survey. In September 1996, the same procedures were followed to send a second survey to members who responded to the first survey. The study was approved in advance and monitored by the HealthPartners Institutional Review Board.

\section{Study subjects}

All members aged 40 and over who were enrolled on December 15, 1994 were potential subjects for the study. The sample comprised three strata of members who had been diagnosed with none, one, or two or more of four chronic conditions, respectively. Diagnoses of diabetes, heart disease, hypertension, and dyslipidemia were assigned to members based on 1994 administrative data using International Classification of Diseases, 9th Revision, Clinical Modification (ICD-9-CM) coding and pharmacotherapy databases.

A diagnosis of diabetes was assigned if the member had two or more ICD-9 codes 250.xx, or a filled prescription for a diabetes-specific drug such as insulin, a sulfonylurea, or a biguanide. Heart disease was assigned if the member had one or more ICD-9 codes 412, 413.9, 429.2, or 428.0. Hypertension was assigned if the member had one or more ICD-9 codes 401, 401.1, or 401.9. Dyslipidemia was assigned if the member had an ICD-9 code of 272.4. A more detailed description of the identification of members with specific conditions and the sensitivity, specificity, and positive predictive value of this method has been previously published [6].

A random sample of 3,000 members $(1.89 \%)$ were selected from 158,415 members with none of the four chronic conditions; 2,500 members $(7.3 \%)$ were selected from the 34,159 members who had one condition; and 2,500 (33\%) were selected from the 7,571 members who had two or more conditions. Hence, the total study population included a stratified random sample of 8,000 individuals aged 40 and older.

\section{Sample exclusions}

Of 8,000 initial sample subjects, 533 were unable to complete the first survey due to death, disenrollment, mailing address problems, language, or other problems, leaving 7,467 eligible. Of these, 5,975 responded (80\% response rate) to the first survey. Of these, 4,067 also responded to the Year 2 survey, representing roughly $55 \%$ of the eligible sample and $68 \%$ of the first survey respondents. We limited the analysis to those 50 years of age or older at baseline, because younger subjects $(n=963)$ have relatively low and stable health care charges, thus contributing little information to the dependent variable. To avoid potential confounding between our primary outcome of interest (changes in annual health care charges between 1995 and 1997) and changes in the capacity to be physically active, we excluded from the analysis subjects who reported any level of physical impairment at either survey $(n=710)$. Exclusion of individuals who were not continuously enrolled throughout the 3-year study period (6\%) did not materially alter our results. Thus, we have retained these subjects in the analyses presented below. Based on examination of regression residuals for excessively influential cases, we excluded one subject from the analysis due to a very large Cook $D$ statistic $(>1.5)$. After these exclusions, our analytic sample consisted of $N=2,393$ subjects.

\section{Data definitions}

Similar survey instruments (approximately 60 questions each) were administered in 1995 and 1996, and included items on demographics, health status, use of preventive services, modifiable health risks, and readiness to change modifiable health risks. The core of the survey items was adapted from the Centers for Disease Control and Prevention's Behavioral Risk Factor Surveillance System, which has reliability coefficients for behavioral risk factors above 0.70 [7].

\section{Dependent variable}

The primary outcome variable in the analysis was the total of health care charges gathered from the HealthPartners claims system. Each encounter in either an owned or contracted clinic generated a claim/charge that included inpatient and outpatient claims for both facilities and professional fees, exclusive of pharmaceuticals. All charges were adjusted to 1997 dollars using the Consumer Price Index and then difference scores were computed by subtracting total charges billed during Year 0 of the study (1 September 1994 to 31 August 1995, the period on which subjects reported in the first survey) from total charges billed in Year 2 (1 September 1996 to 31 August 1997, the year after the second survey). Charges for Year 1 (1 September 1995 to 31 August 1996, the period reported on by subjects in the second survey) are not considered in the construction of the dependent variable. Adjustment for re- 
gression to the mean was accomplished using the method proposed by Chuang-Stein and Tong [8]. This method essentially reduces an individual's raw difference score by an amount determined by the product of (1) the distance of their charges at Year 0 from the grand mean of Year 0 charges, and (2) the correlation between their Year 0 and Year 2 charges minus 1 . The sampling structure of the survey required that we weight each observation based on its sampling probability to obtain population estimates. These weights were included in all multivariate analyses using standard methods [9].

\section{Independent variable}

The independent variable of primary interest was change in physical activity status between the end of Year 0 and the end of Year 1. Physical activity was assessed via self-report and quantified in relation to recommended health-related guidelines [10]. At each survey, respondents reported whether, in the past week, they "have gotten a total of 30 minutes or more" of physical activity, and on how many days in the past week they had gotten this much physical activity. We used these two items from each survey to classify individuals as being either "active" or "inactive" at each of the two time points. To evaluate the sensitivity of our findings to alternative definitions of physical activity, we created five definitions of inactivity and activity:

\begin{tabular}{lll} 
Definition & Inactive & Active \\
\hline A & 0 days & $1+$ days \\
B & 0 days & $2+$ days \\
C & $0-1$ day & $2+$ days \\
D & $0-1$ day & $3+$ days \\
E & $0-1$ day & $4+$ days
\end{tabular}

We then used these definitions to classify the physical activity status of each study subject into one of five mutually exclusive groups, based on their reported physical activity at both surveys:

\begin{tabular}{lll} 
Group & Year 0 & Year 1 \\
\hline I, I & (I)nactive & (I)nactive \\
A, A & (A)ctive & (A)ctive \\
A, I & (A)ctive & (I)nactive \\
I, A & (I)nactive & (A)ctive \\
U & \multicolumn{2}{c}{ "Unclassified" in either year }
\end{tabular}

"Unclassified" refers to respondents who reported days of physical activity at either the first or the second survey that fell within the "gap" between the inactive and active categories under definitions B, D, and E. This category was created to reduce misclassification of change in physical activity by requiring a larger change to cross the activity/ inactivity threshold. We also created a dummy variable indicating respondents who had missing data for physical activity at either survey.

\section{Covariates}

Covariates included in the analysis were age, gender, chronic disease status, smoking status, and body mass index (BMI). Prior research has shown that health care charges are associated with these variables before and after adjustment for functional health status and other factors [11,12]. Age and gender were obtained from HMO administrative databases. Age was calculated in years from date of birth to the date of the first survey and is centered on its mean for the analysis. Gender is represented as a dummy variable with female as the reference category. Due to the lack of variability in the sample with respect to race (more than 95\% white), we did not include it as a covariate in these analyses.

Comorbidity was assessed by using a modified Charlson score. The score was calculated using ICD-9-CM diagnostic codes [13], with diagnoses identified over a 12-month period preceding the first survey. Members without medical care experience during the period were assigned a missing value for Charlson and did not appear in subsequent analysis. Members with experience but none of the 19 chronic conditions within the Charlson index were assigned a score of zero. Because outpatient encounters may contain "ruleout" coding, for a member to receive a weight in one of the Charlson conditions he or she must have had two or more diagnoses within that condition. Both primary and secondary ICD-9 codes were included. Even though the distribution of the Charlson score was positively skewed, results from multivariate models substituting a logged Charlson score were not different from multivariate models with the original variable. Hence, the models with the originally scaled variable are included for ease of interpretation.

Respondents who reported ever having smoked at least 100 cigarettes through Year 0 and that they were smoking as of Year 1 were defined as current smokers. Those who reported ever having smoked at least 100 cigarettes but who denied currently smoking were defined as former smokers. Never smokers were those individuals who denied ever having smoked 100 cigarettes and were the reference category in the analyses.

Body mass index at the end of Year 0 was calculated as self-reported body weight in kilograms divided by selfreported height in meters squared $\left(\mathrm{kg} / \mathrm{m}^{2}\right)$, and was centered on its mean value.

\section{Analytic model}

We estimated ordinary least-squares regression models predicting the effect of changes in physical activity from the end of Year 0 to the end of Year 1 on changes in charges billed between Years 0 and 2, adjusting for age, sex, categorical modified Charlson score, smoking status, and BMI. As mentioned above, all multivariate models adjusted for regression to the mean and used sample weighting to obtain population representation. All analyses were conducted using SAS Version 8.2. We tested the homogeneity of regression assumption by estimating regression models predicting 
Table 1

Descriptive statistics for analytic sample

\begin{tabular}{lrcc}
\hline Variable & $N^{\mathrm{a}}$ & Mean $^{\mathrm{b}}(\%)$ & $\mathrm{SD}$ \\
\hline Age (years) & 2,393 & 63 & 5 \\
Male & 1,130 & 43 & - \\
Charlson (modified) categories at baseline & & & \\
$\quad 0$ & 1,471 & 78 & - \\
$\quad$ & 766 & 19 & - \\
$\quad$ or 2 & 156 & 3 & - \\
$\quad 3$ & & & \\
Smoking status in Year 0 & 962 & 43 & - \\
$\quad$ Never smoker & 244 & 13 & - \\
$\quad$ Current smoker & 1,138 & 43 & - \\
Former smoker & 49 & 2 & - \\
$\quad$ Missing smoking info & 2,393 & 26.19 & 2.81 \\
Body mass Index (kg/m ${ }^{2}$ ) in Year 0 & & & \\
Chronic disease diagnosis strata at Year 0 & 644 & 71.8 & - \\
$\quad$ None of four & 862 & 23.1 & - \\
$\quad$ One of four & 887 & 5.1 & - \\
$\quad$ Two or more of four & 2,293 & 2.9 & 1.3 \\
Physical activity days/week in Year 0 & 2,314 & 2.9 & 1.3 \\
Physical activity days/week in Year 1 & 2,393 & 3109 & 4097 \\
Total charges in Year 0 & 2,393 & 3962 & 5982 \\
Total charges in Year 1 & 2,393 & 3779 & 5257 \\
Total charges in Year 2 & & & \\
\hline
\end{tabular}

${ }^{a}$ Unweighted $N$ 's.

${ }^{\mathrm{b}}$ Weighted means and proportions.

total costs in Year 2 as a function of a main effect for total charges in Year 0, a main effect for physical activity group, and an interaction term between Year 0 charges and physical activity group. We found no significant interactions between any of the physical activity measures and Year 0 charges, indicating that the assumption was met and that correlations between Year 0 charges and Year 2 charges did not vary significantly across physical activity groups.

\section{Results}

Table 1 presents descriptive statistics of our analytic sample. Mean age is 63, and there are more women than men in the sample. Most are not current smokers, though a large proportion (43\%) are former smokers. The sample is somewhat overweight on average, with a mean BMI of 26.2 $\mathrm{kg} / \mathrm{m}^{2}$. The strata reflect the proportion of individuals in the population with one or more diagnosed chronic conditions and this table demonstrates the impact of our reweighting the sample to obtain population estimates. The Charlson categories generally reflect what we see in the sampling strata. Total charges increased substantially from Year 0 to Year 1, with a somewhat smaller decline in total charges from Year 1 to Year 2. On average, people reported being active 3 days a week in both Years 0 and year one. We know from other analyses of these data that this stability in the mean represents a roughly equal number of individuals cycling in and out of being physically active [14].

Table 2 presents similar descriptive statistics for our primary variable of interest: change in physical activity. In this table we see that across definitions of physical activity, between one-quarter and one-half of individuals are active at both observations; between 12 and $16 \%$ are inactive at both observations; between 5 and $10 \%$ become active; and between 5 and $13 \%$ become inactive.

Table 3 presents a series of multivariate models predicting change in charges, as a difference-score, from physical activity change status. All models adjust for age, gender, comorbidity, smoking status, and BMI. The models include indicator variables for missing data on physical activity change status and smoking status to minimize the amount of sample loss due to survey item non-response.

Across columns of Table 3, the models differ only in

Table 2

Descriptive statistics of primary independent variables: analytic sample

\begin{tabular}{lrr}
\hline Physical activity change measures 1995-1996 & $N^{\mathrm{a}}$ & $\%^{\mathrm{b}}$ \\
\hline Definition A: Inactive $=0$ days/week, Active & & \\
1 + day/week & & \\
Physical activity group & 320 & \\
I, I (inactive, inactive) & 227 & 12.2 \\
I, A (inactive, active) & 1,409 & 58.5 \\
A, A (active, active) & 264 & 12.0 \\
A, I (active, inactive) & 173 & 7.1 \\
Missing data &
\end{tabular}

Definition B: Inactive $=0$ days/week, Active $=$ $2+$ days/week

Physical activity group

I, I

I, A

A, A

A, I

$\mathrm{U}$ (Unclassified)

Missing data

$1,256-50.7$

$230 \quad 10.2$

$217 \quad 11.1$

Definition C: Inactive $=0-1$ day/week, Active $=$ $2+$ days/week

Physical activity group

I, I

I, A

A, A

1,256

12.6

A, I

Missing data

Definition D: Inactive $=0-1$ day/week, Active $=$ $3+$ days/week

Physical activity group

I, I

I, A

A, A

A, I

U

Missing data

Definition E: Inactive $=0-1$ day/week, Active $=$ $4+$ days/week

Physical activity group

I, I

I, A

A, A

A, I

$\mathrm{U}$

Missing data

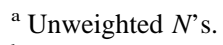

${ }^{\mathrm{b}}$ Weighted proportions. 
Table 3

Multivariate models of change in charges between 1995 and 1997 among sample ages 50+ in 1995

\begin{tabular}{|c|c|c|c|c|c|}
\hline & \multicolumn{5}{|l|}{$b$} \\
\hline & $\begin{array}{l}\text { PA Def A } \\
\text { Inactive }=0, \\
\text { Active }=1+\end{array}$ & $\begin{array}{l}\text { PA Def B } \\
\text { Inactive }=0 \\
\text { Active }=2+\end{array}$ & $\begin{array}{l}\text { PA Def C } \\
\text { Inactive }=0-1, \\
\text { Active }=2+\end{array}$ & $\begin{array}{l}\text { PA Def D } \\
\text { Inactive }=0-1, \\
\text { Active }=3+\end{array}$ & $\begin{array}{l}\text { PA Def E } \\
\text { Inactive }=0-1, \\
\text { Active }=4+\end{array}$ \\
\hline Intercept & $-1,553^{\mathrm{b}}$ & $-1,556^{\mathrm{b}}$ & $-2,053^{\mathrm{c}}$ & $-2,056^{\mathrm{c}}$ & $-2,067^{\mathrm{c}}$ \\
\hline \multicolumn{6}{|l|}{ PA change group } \\
\hline $\mathrm{I}, \mathrm{I}$ & (ref) & (ref) & (ref) & (ref) & (ref) \\
\hline $\mathrm{A}, \mathrm{A}$ & $-1,310^{\mathrm{b}}$ & $-1,214^{\mathrm{a}}$ & -735 & -368 & $-1,034$ \\
\hline $\mathrm{I}, \mathrm{A}$ & $-1,621^{\mathrm{b}}$ & $-1,512^{\mathrm{a}}$ & $-1,367^{\mathrm{a}}$ & $-2,202^{\mathrm{c}}$ & $-1,810^{\mathrm{a}}$ \\
\hline A, I & $-1,634^{b}$ & $-1,881^{b}$ & $-1,064$ & -654 & $-1,572$ \\
\hline $\mathrm{U}$ & - & $-1,687^{\mathrm{b}}$ & - & $-1,374^{\mathrm{b}}$ & -634 \\
\hline Missing & $-2,003^{\mathrm{b}}$ & $-2,000^{\mathrm{b}}$ & $-1,548^{\mathrm{a}}$ & $-1,524^{\mathrm{a}}$ & $-1,551^{\mathrm{a}}$ \\
\hline Age (mean centered) & $64^{\mathrm{c}}$ & $62^{\mathrm{c}}$ & $65^{\mathrm{c}}$ & $61^{\mathrm{c}}$ & $68^{\mathrm{c}}$ \\
\hline Male & -158 & -163 & -179 & -177 & -159 \\
\hline \multicolumn{6}{|l|}{ Charlson score } \\
\hline 0 & (ref) & (ref) & (ref) & (ref) & (ref) \\
\hline $1-2$ & $1,685^{\mathrm{c}}$ & $1,679^{\mathrm{c}}$ & $1,746^{\mathrm{c}}$ & $1,748^{\mathrm{c}}$ & $1,752^{\mathrm{c}}$ \\
\hline $3+$ & $10,616^{\mathrm{c}}$ & $10,558^{\mathrm{c}}$ & $10,720^{\mathrm{c}}$ & $11,121^{\mathrm{c}}$ & $10,942^{\mathrm{c}}$ \\
\hline \multicolumn{6}{|l|}{ Smoking status } \\
\hline Never smoker & (ref) & (ref) & (ref) & (ref) & (ref) \\
\hline Current smoker & $1,957^{\mathrm{c}}$ & $1,998^{\mathrm{c}}$ & $2,040^{\mathrm{c}}$ & $2,048^{\mathrm{c}}$ & $2,006^{\mathrm{c}}$ \\
\hline Former Smoker & $1,022^{\mathrm{b}}$ & $1,047^{\mathrm{b}}$ & $1,036^{\mathrm{b}}$ & $1,035^{\mathrm{b}}$ & $1,011^{\mathrm{b}}$ \\
\hline Missing & $4,381^{\mathrm{c}}$ & $4,425^{\mathrm{c}}$ & $4,520^{\mathrm{c}}$ & $4,475^{\mathrm{c}}$ & $4,357^{\mathrm{c}}$ \\
\hline BMI (mean centered) & $81^{\mathrm{b}}$ & $85^{\mathrm{b}}$ & $84^{\mathrm{b}}$ & $89^{\mathrm{b}}$ & $81^{\mathrm{b}}$ \\
\hline
\end{tabular}

${ }^{\text {a }} P<0.10$.

${ }^{\mathrm{b}} P<0.05$.

${ }^{\mathrm{c}} P<0.01$.

which definition of physical activity is included in the model. Based on face validity, combined with the observation that the average number of days of physical activity per week in this sample is roughly 3 , definition $\mathrm{D}$ is our preferred physical activity definition, as indicated by the shading of this column in Table 3. One pattern to note in this table is that for definitions A and B, all physical activity groups had larger decreases in charges relative to individuals who were inactive at both observations. These declines range from about $-\$ 1,200$ to $-\$ 1,900$. The remaining three physical activity definitions use more stringent criteria to denote change in physical activity, requiring more than one day per week of activity to be considered active. For these three definitions, declines in total charges were observed primarily among individuals who moved from inactivity to activity. In particular, for definition $\mathrm{D}$, compared with the reference category of the consistently inactive, the change in charges was significantly larger for the group that became active $(-\$ 2,200, P<0.01)$. Similar patterns are seen for models using definitions $\mathrm{C}$ and $\mathrm{E}$, though the results for these models do not attain normative levels of significance $(P<0.10)$. We also note that using definition $\mathrm{D}$, the "unclassified" group demonstrates a significantly larger decline in total charges, relative to the consistently inactive $(-\$ 1,374, P<0.05)$.

Table 3 documents significant increases in total charges associated with increases in age, with each additional year of age being associated with a roughly $\$ 65$ increase in total charges $(P<0.01)$. There is no observed effect of sex. And as one would expect, there are substantial and nonlinear increases in charges associated with higher comorbidity. Those with a baseline Charlson score of 1 or 2 experience increases in charges of roughly $\$ 1,700(P<0.01)$ and those with higher Charlson scores experience increases in charges of roughly $\$ 11,000(P<0.01)$. It is also clear that both current and former smokers have significantly higher increases in charges relative to never smokers and that the increase for current smokers is roughly twice that observed for former smokers $(\$ 2,000, P<0.01$, and $\$ 1,000, P<$ 0.05 , respectively). Finally, each one-unit increase in BMI above mean BMI was associated with a roughly $\$ 85$ increase in charges $(P<0.05)$.

In Table 4, we present interpretive information to make the results in Table 3 more intuitively understandable. The top of Table 4 presents the observed total charges in Year 0 while the bottom presents the predicted change in charges from Year 0 to Year 2. One pattern to note is that, with the possible exception of the "unclassified" category, the Year 0 charges appear roughly comparable across physical activity groups, hovering near $\$ 1,500$, depending on which physical activity definition is considered. This is of interest because it demonstrates that any predicted differences across physical activity groups would be driven by the predicted changes in charges rather than divergent total charges at baseline. The bottom of Table 4 presents leastsquares means of changes in charges for all physical activity 
Table 4

Least squares means for physical activity groups by definition of active/inactive

\begin{tabular}{|c|c|c|c|c|c|c|c|c|c|c|}
\hline & $\begin{array}{l}\text { PA Def A } \\
\text { Inactive }=0, \\
\text { Active }=1+\end{array}$ & $N$ & $\begin{array}{l}\text { PA Def B } \\
\text { Inactive }=0, \\
\text { Active }=2+\end{array}$ & $N$ & $\begin{array}{l}\text { PA Def C } \\
\text { Inactive }=0-1, \\
\text { Active }=2+\end{array}$ & $N$ & $\begin{array}{l}\text { PA Def D } \\
\text { Inactive }=0-1, \\
\text { Active }=3+\end{array}$ & $N$ & $\begin{array}{l}\text { PA Def E } \\
\text { Inactive }=0-1, \\
\text { Active }=4+\end{array}$ & $N$ \\
\hline \multicolumn{11}{|c|}{1995 charges (actual) } \\
\hline I, I & $\$ 1,442$ & 320 & $\$ 1,442$ & 320 & $\$ 1,305$ & 395 & $\$ 1,305$ & 395 & $\$ 1,305$ & 395 \\
\hline $\mathrm{A}, \mathrm{A}$ & $\$ 1,736$ & 1,409 & $\$ 1,786$ & 1,256 & $\$ 1,786$ & 1,256 & $\$ 1,511$ & 952 & $\$ 1,021$ & 582 \\
\hline $\mathrm{I}, \mathrm{A}$ & $\$ 1,195$ & 227 & $\$ 1,193$ & 197 & $\$ 1,496$ & 280 & $\$ 1,177$ & 186 & $\$ 1,434$ & 123 \\
\hline $\mathrm{A}, \mathrm{I}$ & $\$ 1,764$ & 264 & $\$ 1,817$ & 230 & $\$ 1,665$ & 289 & $\$ 1,204$ & 197 & $\$ 1,653$ & 107 \\
\hline $\mathrm{U}$ & - & - & $\$ 1,461$ & 217 & - & - & $\$ 2,213$ & 490 & $\$ 1,959$ & 1,013 \\
\hline Missing & $\$ 2,421$ & 173 & $\$ 2,421$ & 173 & $\$ 2,421$ & 173 & $\$ 2,421$ & 173 & $\$ 2,421$ & 173 \\
\hline \multicolumn{11}{|c|}{ Change 1995-1997 (predicted) ${ }^{\mathrm{a}}$} \\
\hline I, I & $\$ 722$ & 320 & $\$ 720$ & 320 & $\$ 265$ & 395 & $\$ 266$ & 395 & \$ 276 & 395 \\
\hline $\mathrm{A}, \mathrm{A}$ & $-\$ 588$ & 1,409 & $-\$ 494$ & 1,256 & $-\$ 470$ & 1256 & $-\$ 102$ & 952 & $-\$ 758$ & 582 \\
\hline $\mathrm{I}, \mathrm{A}$ & $-\$ 899$ & 227 & $-\$ 792$ & 197 & $-\$ 1,101$ & 280 & $-\$ 1,936$ & 186 & $-\$ 1,534$ & 123 \\
\hline A, I & $-\$ 912$ & 264 & $-\$ 1,161$ & 230 & $-\$ 798$ & 289 & $-\$ 388$ & 197 & $-\$ 1,296$ & 107 \\
\hline $\mathrm{U}$ & - & - & $-\$ 967$ & 217 & - & - & $-\$ 1,107$ & 490 & $-\$ 358$ & 1,013 \\
\hline Missing & $-\$ 1,281$ & 173 & $-\$ 1,280$ & 173 & $-\$ 1,283$ & 173 & $-\$ 1,258$ & 173 & $-\$ 1,276$ & 173 \\
\hline
\end{tabular}

${ }^{\text {a }}$ Least-squares means describe the predicted change in charges for each physical activity group for a woman of average age and BMI who is a never smoker with modified Charlson score of 0 .

change categories, predicted from the corresponding multivariate models in Table 3. Of necessity, the patterns observed here are consistent with those observed in Table 3. However, these estimates yield the more intuitively appealing predicted change in charges for each physical activity change group under the assumption that all other model variables are held at their mean values and controlling for unequal group sizes. That is, these figures demonstrate the effect of physical activity change group for a hypothetical 63-year-old female never smoker with a BMI of $26.2 \mathrm{~kg} / \mathrm{m}^{2}$ and a Charlson score of 0 . Focusing on definition $\mathrm{D}$, the bottom of Table 4 shows a predicted (positive) change in charges for such a hypothetical woman who was in the Inactive, Inactive group of \$266. By contrast, the change in charges for a similar woman who was in the Inactive, Active group was predicted to be $-\$ 1,936$. The linkage between the bottom of Table 4 and the results in Table 3 can be seen by noting that the difference between the predicted values of $\$ 266$ and $-\$ 1,936$ is $-\$ 2,202$, equivalent to the value of the parameter estimate for the Inactive, Active group in Table 3.

\section{Discussion}

The results of this study indicate that adults aged 50 and older who initiate a physically active lifestyle have significantly lower short-term health care charges than those who remain inactive. This finding suggests that investments to increase physical activity levels in older adults may be worthwhile, because higher activity levels appear to confer both clinical and economic benefits $[1,4,5]$.

From the clinical point of view, these results extend previous work suggesting that physical activity is positively related to health outcomes [1]. Others have shown that physical activity and increased fitness are associated with lower all-cause and coronary heart disease mortality [15, 16] and charges [4]. However, this is the first study to examine the effect of changes in physical activity status on changes in health care charges. Our findings indicate that most physically inactive individuals who are capable of being more physically active should be strongly encouraged to do so.

The potential savings in health care expenditures should be weighed against the costs of investment in effective programs to increase physical activity. The present study did not assess the magnitude of investments needed to increase population levels of physical activity. However, based on the estimated \$2,200 annual savings from improving physical activity patterns using definition D, and applying a cost-effectiveness model developed in previous work $[17,18]$, we estimate that providing brief annual assessments and brief physical activity counseling from ages 50 to 79 would be extremely cost-effective (approximately $\$ 10,000$ per Quality Adjusted Life Year Saved) from the payer perspective.

Research has documented associations between physician advice and motivational readiness to change [19, 20], and actual behavior change [21] for behaviors such as smoking. Unfortunately, while physicians have often been exhorted to advise and support increased physical activity in patients, such counseling is still not a common practice [22, 23]. Moreover, clinician-based advice has typically been a relatively weak motivator of physical activity behavior change [24,25]. However, the adoption of recent preventive health recommendations, including the use of the "Five A's" approach [26], offers the possibility of greatly increasing the effectiveness of clinic-based advice to change behavior. To further augment the effectiveness of this approach with respect to behaviors such as physical activity, non-clinic-based methods for promoting physical activity should be considered. Various programs and interventions 
are available, with varying levels of cost and effectiveness [27-29]. Group-based interventions are one such method, though other methods may offer more opportunity for "tailoring" to individual needs and preferences. These include telephone, mail-based, and internet-based interventions [30-34].

Many older adults are at risk for, or already have, cardiovascular or other chronic diseases, and may be subject to potential adverse outcomes with rapid transition from a sedentary state to vigorous exercise. However, walking is a preferred mode of physical activity and therefore a reasonable place to begin a physical activity regimen. Walking is a relatively low intensity mode of activity, does not usually require costly and elaborate equipment, and may not require diagnostic testing prior to initiation [35]. Programs may be designed to maintain long-term physical activity, reduce the likelihood of relapse to inactivity, or focus on other modes of exercise such as strength training, balance, and flexibility.

The fact that medical care costs go down when physical activity increases may lead some health plans, medical groups, employers, or payers to more actively support a physically active lifestyle for individuals and populations. Indeed, these data suggest that modest investments in programs to promote or maintain physical activity may have a positive return on investment in some groups of health plan members, patients, or employees. This has been proposed by others $[27,36]$ on the basis of more limited data. The present study suggests that many health plan members aged 50 and older may benefit. The amount that charges declined provides a rough estimate of the limit to which resource allocation may go, without increasing short-term costs.

The data further suggest that the return on investment may occur over a relatively short time horizon. Changes in activity were monitored over a 1-year period, and reduced charges were observed within the following 12 months. This is a substantially shorter period than has been previously reported $[27,36]$. This observation, coupled with recent reports indicating that health plan disenrollment is modest at older ages [37], may increase the attractiveness of such interventions to purchasers and payers of health care.

Physical activity status predicts change in charges among those 50 and older, but not among those in their forties. Increased activity is known to confer biological benefit in younger adults. However, a longer time frame may be needed to observe economic savings since overall health care charges are generally lower in young adults. Hence, the opportunity for absolute cost reductions is greatest in older adults. The prevalence of completely sedentary behavior among adults aged 55 and older was approximately $35 \%$. This suggests a significant opportunity for health care cost reduction through increased physical activity in this group [38].

In sensitivity analyses, those in the active to inactive group had reductions in charges in only two of the five models, while those in the inactive to active group had statistically significant reductions in charges in all five mod- els. Moreover, we do not observe a significant reduction in charges for the active to inactive group in the model using our preferred physical activity grouping (definition D) or any of the models using definitions of physical activity that require more than 2 days per week for an individual to be considered active. Thus, the declining charges observed for the active to inactive group using definitions A and B may suggest misclassification of physical activity status, whereby individuals could be classified as "active" with relatively minimal activity levels. A different potential explanation is a carryover of health benefits derived from prior physical activity. People who have recently become inactive retain some of the cardiovascular fitness or other protective effects of prior physical activity. These residual benefits may temporarily buffer them against the higher short-term health care charges associated with physical inactivity.

As is true of all survey research, methodological factors constrain the interpretation of these data. First, the observational nature of the data means that unmeasured or statistically uncontrolled differences between groups may partly explain the observed differences in charges. Second, although the survey response rates were quite robust, selection effects related to survey nonresponse might have introduced bias. Third, generalization of these results to other settings requires caution because the study was conducted in a single population in the upper Midwest.

These limitations should be balanced against several unique strengths of the present study. First, the study used a cohort design allowing for observation of within-subject change over time. Second, objective measures of health care expenditures came directly from administrative data and were virtually complete. Third, we were able to control for several important potential confounding variables including: BMI, smoking status, diagnosed chronic conditions, age, and sex. Fourth, the pattern of findings persisted across a range of measures of change in physical activity.

We conclude that maintaining or increasing physical activity in those aged 50 and older is associated with a short-term reduction in annualized health care charges. More work is needed to elucidate the precise mechanism of impact of exercise on costs. The data underscore the importance of current clinical and community initiatives designed to increase physical activity. The data enable health plan managers and public health planners to estimate the potential return on investment for resources that may be allocated to improve or maintain individual or population levels of physical activity.

\section{Acknowledgments}

This study was supported by a contract from HealthPartners to HealthPartners Research Foundation. The authors acknowledge the support of George Isham, M.D., in the conceptualization of this study. 


\section{References}

[1] Physical activity and health: a report of the surgeon general. Atlanta, GA: U.S. Department of Health and Human Services, Centers for Disease Control and Prevention, National Center for Chronic Disease Prevention and Health Promotion; 1996.

[2] Pronk N, Boyle R, O'Connor P. The association between physical fitness and diagnosed chronic disease in health maintenance organization members. Am J Health Promot 1998;12:300-6.

[3] Blair SN, Applegate WB, Dunn AL, et al. Activity Counseling Trial (ACT): rationale, design, and methods. Activity Counseling Trial Research Group. Med Sci Sports Exerc 1998;30:1097-106.

[4] Pronk NP, Goodman MJ, O'Connor PJ, Martinson BC. Relationship between modifiable health risks and short-term health care charges. JAMA 1999;282:2235-9.

[5] Goetzel RZ, Anderson DR, Whitmer RW, Ozminkowski RJ, Dunn RL, Wasserman J. The relationship between modifiable health risks and health care expenditures: an analysis of the multi-employer HERO health risk and cost database. The Health Enhancement Research Organization (HERO) Research Committee. J Occup Environ Med 1998;40:843-54.

[6] O'Connor P, Rush W, Pronk N. Database systems to identify biological risk in managed care organizations: implications for clinical care. J Ambulatory Care Manage 1997;20:17-23.

[7] Stein A, Lederman R, Shea S. The Behavioral Risk Factor Surveillance System questionnaire: its reliability in a statewise sample. Am J Public Health 1993;83:1768-72.

[8] Chuang-Stein C, Tong D. The impact and implication of regression to the mean on the design and analysis of medical investigations. Statist Methods Med Res 1997;6:115-28.

[9] Hosmer D, Lemeshow S. Applied logistic regression. New York: Wiley, 1989.

[10] Pate R, Pratt M, Blair S, et al. Physical activity and public health: a recommendation from the Centers for Disease Control and Prevention and the American College of Sports Medicine [see comments]. JAMA 1995;273:402-7.

[11] Hornbrook MC, Goodman MJ. Assessing relative health plan risk with the RAND-36 health survey. Inquiry 1995;32:56-74.

[12] Hornbrook MC, Goodman MJ. Chronic disease, functional health status, and demographics: a multi-dimensional approach to risk adjustment. Health Serv Res 1996;31:283-307.

[13] Deyo R, Cherkin D, Ciol M. Adapting a clinical comorbidity index for use with ICD9-CM administrative databases. J Clin Epidemiol 1992;45:613-9.

[14] Pronk N, Tan A, O'Connor P, Gray C. Identifying the potential to increase physical activity using stages of change in HMO members. Med Sci Sports Exerc 1998;30:S308.

[15] Paffenbarger R, Hyde R, Wing A, Lee I, Jung D, Kampert J. The association of changes in physical activity level and other lifestyle characteristics with mortality amoung men. N Engl J Med 1993;328: $538-45$.

[16] Blair S, Kohl H, Barlow C, Paffenbarger R, Gibbons L, Macera C. Changes in physical fitness and all-cause mortality: a prospective study of healthy and unhealthy men. JAMA 1995;273:1093-8.

[17] Maciosek MV, Coffield AB, McGinnis JM, et al. Methods for priority setting among clinical preventive services. Am J Prev Med 2001;21: $10-9$.

[18] Coffield AB, Maciosek MV, McGinnis JM, et al. Priorities among recommended clinical preventive services. Am J Prev Med 2001;21: $1-9$.
[19] Boyle R, O'Connor P, Pronk N, Tan A. Stages of change for physical activity, diet, and smoking among HMO members with chronic conditions. Am J Health Promot 1998;12:170-5.

[20] O’Connor PJ, Rush WA, Prochaska JO, Pronk NP, Boyle RG. Professional advice and readiness to change behavioral risk factors among members of a managed care organization. Am J Manag Care 2001;7:125-30.

[21] Lancaster T, Stead L, Silagy C, Sowden A. Regular review: effectiveness of interventions to help people stop smoking: findings from the Cochrane Library. BMJ 2000;321:355-8.

[22] Abramson S, Stein J, Schaufele M, Frates E, Rogan S. Personal exercise habits and counseling practices of primary care physicians: a national survey. Clin J Sport Med 2000;10:40-8.

[23] Glasgow RE, Eakin EG, Fisher EB, Bacak SJ, Brownson RC. Physician advice and support for physical activity: results from a national survey. Am J Prev Med 2001;21:189-96.

[24] Effects of physical activity counseling in primary care: the Activity Counseling Trial: a randomized controlled trial. JAMA 2001;286: 677-87.

[25] Lawlor DA, Hanratty B. The effect of physical activity advice given in routine primary care consultations: a systematic review. J Public Health Med 2001;23:219-26.

[26] Evaluating primary care behavioral counseling interventions: an evidence-based approach (background article). Originally in Am J Prev Med 2002;22:267-84.

[27] Shephard RJ. Twelve years experience of a fitness program for the salaried employees of a Toronto life assurance company. Am J Health Promot 1992;6:292-301.

[28] Pelletier K. Clinical and cost outcomes of multifactorial, cardiovascular risk management interventions in worksites: a comprehensive review and analysis. J Occup Environ Med 1997;39:1154-69.

[29] Ozminkowski R, Dunn R, Goetzel R, Cantor R, Murname J, Harrison M. A return on investment evaluation of the Citibank, N.A., Health Management Program. Am J Health Promot 1999;14:31-43.

[30] Castro CM, King AC, Brassington GS. Telephone versus mail interventions for maintenance of physical activity in older adults. Health Psychol 2001;20:438-44.

[31] Tate DF, Wing RR, Winett RA. Using Internet technology to deliver a behavioral weight loss program. JAMA 2001;285:1172-7.

[32] Bock BC, Marcus BH, Pinto BM, Forsyth LH. Maintenance of physical activity following an individualized motivationally tailored intervention. Ann Behav Med 2001;23:79-87.

[33] Marcus BH, Emmons KM, Simkin-Silverman LR, et al. Evaluation of motivationally tailored vs. standard self-help physical activity interventions at the workplace. Am J Health Promot 1998;12:246-53.

[34] Kreuter MW, Strecher VJ. Do tailored behavior change messages enhance the effectiveness of health risk appraisal? Results from a randomized trial. Health Educ Res 1996;11:97-105.

[35] Durstine JL, King AC, Painter PL, Roitman JL, editors. ACSM's resource manual for guidelines for exercise testing and prescription. American College of Sports Medicine; 1993.

[36] Edington D, Yen L, Witting P. The financial impact of changes in personal health practices. J Occup Environ Med 1997;39:103746.

[37] Legorreta A, Meng Y, Keung K, Lin Z, Davidson M. Diabetes and disenrollment in a health maintenance organization setting. Diabetes Care 1999;22:1487-9.

[38] Department of Health and Human Services. Surveillance for five health risks among older adults-United States, 1993-1997. MMWR CDCSurveill Summ 1999;48(SS08):89-130. 